\title{
Upregulation of Leukocyte Immunoglobulin-Like Receptor B4 on Interstitial Macrophages in COPD; Their Possible Protective Role Against Emphysema Formation
}

\section{Ayumi Mitsune}

Tohoku University School of Medicine: Tohoku Daigaku Daigakuin Igakukei Kenkyuka Igakubu

Mitsuhiro Yamada ( $\square$ yamitsu@med.tohoku.ac.jp)

Tohoku University Graduate School of Medicine https://orcid.org/0000-0002-0832-1939

Naoya Fujino

Tohoku University School of Medicine: Tohoku Daigaku Daigakuin Igakukei Kenkyuka Igakubu

\section{Tadahisa Numakura}

Tohoku University School of Medicine: Tohoku Daigaku Daigakuin Igakukei Kenkyuka Igakubu

\section{Tomohiro Ichikawa}

Tohoku University School of Medicine: Tohoku Daigaku Daigakuin Igakukei Kenkyuka Igakubu Ayumi Suzuki

Tohoku University School of Medicine: Tohoku Daigaku Daigakuin Igakukei Kenkyuka Igakubu

\section{Shuichiro Matsumoto}

Tohoku University School of Medicine: Tohoku Daigaku Daigakuin Igakukei Kenkyuka Igakubu

\section{Yoshiya Mitsuhashi}

Tohoku University School of Medicine: Tohoku Daigaku Daigakuin Igakukei Kenkyuka Igakubu

\section{Koji Itakura}

Tohoku University School of Medicine: Tohoku Daigaku Daigakuin Igakukei Kenkyuka Igakubu

\section{Tomonori Makiguchi}

Tohoku University School of Medicine: Tohoku Daigaku Daigakuin Igakukei Kenkyuka Igakubu

\section{Akira Koarai}

Tohoku University School of Medicine: Tohoku Daigaku Daigakuin Igakukei Kenkyuka Igakubu

\section{Tsutomu Tamada}

Tohoku University School of Medicine: Tohoku Daigaku Daigakuin Igakukei Kenkyuka Igakubu

\section{Shota Endo}

Tohoku University Institute of Development Ageing and Cancer: Tohoku Daigaku Karei Igaku Kenkyujo Toshiyuki Takai

Tohoku University School of Medicine: Tohoku Daigaku Daigakuin Igakukei Kenkyuka Igakubu

\section{Yoshinori Okada}

Tohoku University Institute of Development Ageing and Cancer: Tohoku Daigaku Karei Igaku Kenkyujo 


\section{Satoshi Suzuki}

Tohoku University School of Medicine: Tohoku Daigaku Daigakuin Igakukei Kenkyuka Igakubu Masakazu Ichinose

Tohoku University School of Medicine: Tohoku Daigaku Daigakuin Igakukei Kenkyuka Igakubu Hisatoshi Sugiura

Tohoku University School of Medicine: Tohoku Daigaku Daigakuin Igakukei Kenkyuka Igakubu

\section{Research}

Keywords: Pulmonary Macrophage, Matrix Metalloproteinase 12, Pulmonary Emphysema

Posted Date: July 27th, 2021

DOI: https://doi.org/10.21203/rs.3.rs-723302/v1

License: (c) (1) This work is licensed under a Creative Commons Attribution 4.0 International License.

Read Full License 


\section{Abstract}

Background: Leukocyte immunoglobulin-like receptor B4 (LILRB4) is one of the inhibitory receptors in various types of immune cells including macrophages. Previous reports suggested that LILRB4 could be involved in a negative feedback system to prevent excessive inflammatory responses. However, its role has been unclear in chronic obstructive pulmonary disease (COPD), in which macrophages play a crucial role in the pathogenesis. In this study, we aimed to examine the changes of LILRB4 on macrophages both in the lung specimens of COPD patients and the lungs of a mouse emphysema model. We then tried to compare the differences in both inflammation and emphysematous changes of the model between wildtype and LILRB4-deficient mice in order to elucidate the role of LILRB4 in the pathogenesis of COPD.

Methods: We prepared single-cell suspensions of resected lung specimens of never-smokers $(n=21)$, non-COPD smokers $(n=16)$, and COPD patients $(n=14)$. The identification of LILRB4-expressing cells and the level of LILRB4 expression were evaluated by flow cytometry. We analyzed the relationships between the LILRB4 expression and clinical characteristics including respiratory function. In the experiments using an elastase-induced mouse model of emphysema, we also analyzed the LILRB4 expression on lung macrophages. We compared inflammatory cell accumulation and emphysematous changes induced by elastase instillation between wild-type and LILRB4-deficient mice.

Results: The levels of surface expression of LILRB4 are relatively high on monocyte linage cells including macrophages in the human lungs. The percentage of LILRB4 ${ }^{+}$cells in lung interstitial macrophages was increased in COPD patients compared to non-COPD smokers $(p=0.018)$ and correlated with the severity of emphysematous lesions detected by CT scan $\left(r_{s}=0.559, p<0.001\right)$, whereas the amount of smoking showed no correlation with LILRB4 expression. Increased LILRB4 on interstitial macrophages was also observed in elastase-treated mice $(p=0.008)$. LILRB4-deficient mice showed severer emphysematous lesions with increased MMP-12 expression in the model.

Conclusions: LILRB4 on interstitial macrophages was upregulated both in human COPD lungs and in a mouse model of emphysema. This upregulated LILRB4 may have a protective effect against emphysema formation, possibly through decreasing MMP-12 expression in the lungs.

\section{Background}

Chronic obstructive pulmonary disease (COPD) is a chronic respiratory disease caused by long-time inhalation exposure to toxic substances, mostly cigarette smoke [1]. The pathological features of COPD are characterized by both emphysematous changes of the lung parenchyma and inflammation of the small airways [2]. Pharmacological reagents, including bronchodilators and inhaled corticosteroids, are used to reduce symptoms, prevent exacerbations, and improve exercise tolerance and the health status of COPD patients [3]. Inhaled corticosteroids, combined with bronchodilators, are used for COPD patients as an anti-inflammatory therapy [3]. However, it is also true that chorionic inflammation in COPD is steroidresistant [4], so the effects of inhaled corticosteroids against persistent inflammation in COPD are limited. 
Therefore, further exploration for the mechanism of persistent inflammation and the inflammatory cells involved could be important to determine the new drug targets for anti-inflammatory therapy in COPD.

For further understanding of the pathogenesis of chronic inflammation in COPD, we focused on leukocyte immunoglobulin-like receptor B4 (LILRB4) in this study. LILRB4 is one of the inhibitory receptors expressed in various types of immune cells including monocytes and macrophages. LILRB4 is also called immunoglobulin-like transcripts 3 (ILT-3), CD85k, gp49B [5, 6]. Inhibitory receptors are characterized by an intracellular domain called immunoreceptor tyrosine-based inhibition motif (ITIM). Tyrosine phosphatase SHP-1 and SHP-2 are associated upon stimulation and suppress activation signals by the dephosphorylation of tyrosine-phosphorylated proteins $[7,8]$. It has been reported that LILRB4 are involved in the pathogenesis of various diseases such as allergic diseases $[9,10]$, acute lung injury [11], cancer [12-15], autoimmune diseases [16], transplantation immunity [17, 18], nonalcoholic fatty liver disease [19], and infection disease [20]. It has been reported that LILRB4 on monocyte lineage cells including macrophages was upregulated by inflammatory stimuli including lipopolysaccharide [11, 21], suggesting that LILRB4 could be involved in a negative feedback system to prevent excessive inflammatory responses. However, little is known about the expression kinetics and role of LILRB4 in the pathogenesis of COPD.

In this study, we first aimed to analyze the expression of LILRB4 in lung single cells derived from surgically resected lungs of never-smokers, non-COPD smokers, and COPD patients. We examined which type of cells expressed LILRB4 and analyzed the relation of LILRB4 expression to the prevalence of COPD, respiratory function, smoking, and imaging findings. In addition, we analyzed the changes of LILRB4 expression in an elastase-induced mouse model of emphysema. We further examined the inflammatory responses and emphysematous changes in a mouse model of emphysema using both wild-type and LILRB4-deficietnt mice to surmise the role of LILRB4 in the pathogenesis of emphysematous lesions and COPD.

\section{Methods}

\section{Study population}

This study included 51 patients who received surgery for lung cancer in Ishinomaki Red Cross Hospital and Tohoku University Hospital. Patients with respiratory disease other than COPD were excluded. The diagnosis of COPD was determined based on the Global Initiative for Chronic Obstructive Lung Disease (GOLD) guidelines (https://goldcopd.org). The patients were divided into three groups: non-smokers, nonCOPD smokers, and COPD patients. We used the Goddard score for the assessment of low attenuation areas (LAA) [22]. This study was approved by the Ethics Committee at Tohoku University School of Medicine (2017-1-352). Written informed consent was obtained from all patients.

\section{Preparation of human lung single-cell suspensions}


We prepared human single-cell suspension as previously described with some modification [23-26]. Minced lung tissues were incubated with Hanks Balanced Salt Solution (Thermo Fisher Scientific, Waltham, MA, USA) containing $1.5 \mathrm{mg} / \mathrm{ml}$ Collagenase A (Sigma-Aldrich, St. Louis, MO) and $2000 \mathrm{KU} / \mathrm{ml}$ DNase I (Sigma-Aldrich) at $37^{\circ} \mathrm{C}$ for 45 minutes, then minced again with scissors and incubated at $37^{\circ} \mathrm{C}$ for 45 minutes. Single-cell suspensions were filtered with a $100 \mu \mathrm{m}$ cell strainer (BD biosciences) twice and red blood cells were lysed with ammonium-chloride-potassium lysis buffer (Thermo Fisher Scientific). Cells were resuspended in RPMI 1640 medium (containing L-glutamine and 25 mM HEPES; Thermo Fisher Scientific) with $5 \%$ fetal bovine serum and $2 \%$ penicillin-streptomycin-amphotericin $B$ suspension (100 units/ml penicillin, $100 \mu \mathrm{g} / \mathrm{ml}$ streptomycin, and $2.5 \mu \mathrm{g} / \mathrm{ml}$, amphotericin B; FUJIFILM Wako Chemicals, Osaka, Japan) and filtered twice with $70 \mu \mathrm{m}$ cell strainer (BD Biosciences, Franklin Lakes, NJ, USA). Cell numbers were calculated using trypan blue staining and analyzed by flow cytometry.

\section{Mice}

C57BL/6 mice were purchased from Charles River Laboratories Japan (Yokohama, Japan) and 7 to 10week-old female mice were used. LILRB4-deficient mice $\left(\mathrm{gp} 49 \mathrm{~B}^{-/-}\right)$with the B6 background were previously established [27]. All mice were maintained and bred in the Institute for Animal Experimentation, Tohoku University Graduate School of Medicine, under specific pathogen-free conditions. All animal protocols were reviewed and approved by the Animal Studies Committee of Tohoku University.

\section{Elastase-induced emphysema in mouse model}

A mouse model of elastase-induced emphysema was prepared as previously described [26]. Briefly, mice were anesthetized with isoflurane temporarily and were given an intranasal instillation of 3 units porcine pancreatic elastase (FUJIFILM Wako Chemicals) in $50 \mu$ of PBS or $50 \mu \mathrm{l}$ of PBS alone. Analysis of macrophages was conducted on day 7 and histological examination and CT scan were conducted on day 21.

\section{Bronchoalveolar lavage (BAL)}

Mice were injected intraperitoneally with triple mixed anesthesia of medetomidine hydrochloride (0.3 $\mathrm{mg} / \mathrm{kg}$ ), midazolam (4 mg/ $\mathrm{kg}$ ), and butorphanol tartrate $(5 \mathrm{mg} / \mathrm{kg})$. After euthanization by cutting the aorta, we inserted a 20-gauge needle into the trachea. Bronchoalveolar lavage fluid (BALF) was collected by washing the lungs three times with $1 \mathrm{ml}$ of PBS. BALF was centrifuged at $300 \mathrm{rpm}$ for 5 minutes and the supernatant was used for cytokine analysis. Cells were resuspended in PBS and cell counts were determined by a hemocytometer. Cell fractionation was calculated by cytospin slides stained by DiffQuick method.

\section{Preparation of mouse lung single-cell suspensions}


Mouse single-cell suspensions were prepared as previously described with some modification [28]. Lungs chopped with scissors were incubated at $37^{\circ} \mathrm{C}$ for 45 minutes in RPMI solution containing $50 \mu \mathrm{g} / \mathrm{ml}$ Liberase TM (Roche, Basel, Switzerland) and $10 \mu \mathrm{g} / \mathrm{ml}$ DNase I (Roche). The lung tissue was passed through a $40 \mu \mathrm{m}$ cell strainer. After centrifugation, the cell pellets were resuspended in ACK lysis buffer (Thermo-Fischer Scientific) and incubated to remove red blood cells. The samples were washed with PBS and resuspended in the staining buffer for flow cytometric analysis.

\section{Flow cytometry}

Flow cytometry was performed as previously described with some modification [24, 29]. LIVE/DEAD Fixable Dead Cell Stain Kit (Invitrogen, Carlsbad, CA) was added to single-cell suspensions and incubated at $4{ }^{\circ} \mathrm{C}$ for 30 minutes. After resuspension in FACS buffer containing PBS with $0.1 \%$ sodium azide and $2 \%$ FBS, human FcR Blocking Reagent (Miltenyi Biotec) in the case of human and anti-CD16/32 mouse antibody in the case of mouse were added to prevent non-specific staining, then incubated $4{ }^{\circ} \mathrm{C}$ for 5 minutes. Based on previous reports [30-32], we defined human alveolar macrophages as FSC ${ }^{\text {high }} \mathrm{CD} 45^{+} \mathrm{CD} 206^{+} \mathrm{CD} 144^{-}$cells, human interstitial macrophages as $\mathrm{FSC}{ }^{\mathrm{mid}} \mathrm{CD} 45^{+} \mathrm{CD} 206^{+} \mathrm{CD} 14^{+}$cells, mouse alveolar macrophages as $\mathrm{CD} 45^{+} \mathrm{Ly} 6 \mathrm{G}^{-} \mathrm{CD} 64^{+} \mathrm{CD} 24^{-} \mathrm{CD} 11 \mathrm{~b}^{\text {int }} \mathrm{CD} 11 \mathrm{c}^{+}$cells and mouse interstitial macrophages as $\mathrm{CD} 45^{+} \mathrm{Ly} 6 \mathrm{G}^{-} \mathrm{CD} 64^{+} \mathrm{CD} 24^{-} \mathrm{CD} 11 \mathrm{~b}^{+} \mathrm{CD} 11 \mathrm{c}^{-}$cells. Data were collected by LSR Fortessa (BD Bioscience) and analyzed by FCS express 6 software (De Novo Software, Glendale, CA). Cell sorting was performed using FACS Aria II (BD Biosciences). We utilized fluorescence minus one controls to distinguish the positive population from the negative one.

\section{Antibodies}

Brilliant Violet 421-conjugated anti-human CD45 (HI30), APC-conjugated anti-human CD3 (OKT3), APCconjugated anti-human CD19 (HIB19), FITC-conjugated anti-human CD14 (M5E2), CD11c-conjugated anti-human CD11c (3.9), PE-Cy7-conjugated anti-human HLA-DR (LN3), PerCP-Cy5.5-conjugated antihuman CD56 (5.1H11), PE-conjugated anti-human LILRB4 (ZM4.1), Pacific blue-conjugated anti-mouse CD45 (30-F11), Brilliant violet 510-conjugated anti-mouse CD11b (M1/70), PerCP-Cy5.5-conjugated antimouse CD11c (N418), FITC-conjugated anti-mouse Ly6G (1A8), PE-Cy7-conjugated anti-mouse CD64 (X54-5/7.1), APC/Fire 750-conjugated anti-mouse CD24 (M1/69), APC-conjugated anti-mouse IA/IE (M5/114.15.2), PE-conjugated anti-mouse LILRB4 (H1.1), PE-conjugated American Hamster IgG control antibody (HKT888) were purchased from Biolegend. APC conjugated anti-human CD206 (19.2), APCconjugated mouse $\operatorname{lgG}_{1} \mathrm{~K}$ control antibody (P3.6.2.8.1), PE-conjugated mouse $\lg _{1} \mathrm{~K}$ control antibody (P3.6.2.8.1) were purchased from eBiosciences.

\section{Histological analysis}

The lung was refluxed by injecting PBS from the right ventricle. The $10 \%$ neutral buffered formalin was injected from the trachea at a pressure of $30 \mathrm{cmH}_{2} \mathrm{O}$ and the lung was fixed for 24 hours. We entrusted 
the production of paraffin-embedded sections to Experimental Animal pathology Platform Section, Tohoku University. Emphysematous changes were evaluated by the mean liner intercept (MLI) [33].

\section{Image analysis}

Under $2 \%$ isoflurane anesthesia, mouse chest CT scans were performed using an X-ray CT system for laboratory animals (LaTheta LCT-200; Hitachi Aloka Medical Ltd., Tokyo, Japan). Calibration was carried out according to the manufacturer's protocol. The CT value of air was set to -1000 Housefield Units (HU), and water was set to $0 \mathrm{HU}$. Data were converted to DICOM files and analyzed by LaTheta software (version 3.22) and Image $J$ software (National Institutes of Health, Frederick, MD). The quantitative evaluation of emphysema was performed using the percentage of low attenuation area, which was defined as the area from -871 HU to $-610 \mathrm{HU}$ [34].

\section{Quantitative Polymerase Chain Reaction (qPCR)}

RNA was extracted from sorting cells using RNeasy Micro Kit (Qiagen, Valencia, CA) and from lung tissue using RNeasy Mini Kit (Qiagen, Valencia, CA). cDNA was synthesized by the High Capacity RNA-to-cDNA Kit (Thermo Fisher Scientific). Quantitative PCR was conducted on StepOne Plus (Thermo Fisher Scientific) using SYBR Premix Ex Taq (TaKaRa, Kusatsu, Japan).

The levels of mRNA expression were evaluated by the comparative CT method and glyceraldehyde-3phosphate dehydrogenase (GAPDH) was used as an endogenous control gene. The reference sample was one of the PBS-treated control samples or wild-type control samples. Primer sets were as follows: for mouse IL-10: forward, 5'-GCCAGAGCCACATGCTCCTA-3', and reverse, 5'-

GATAAGGCTTGGCAACCCAAGTAA-3'; for mouse IL-1b: forward, 5'-TCCAGGATGAGGACATGAGCAC-3', and reverse, 5'-GAACGTCACACACCAGCAGGTTA-3'; for mouse Mmp12: forward, 5'-

CTCTAGCCAGCACATGACTCCAA-3', and reverse, 5'-CTGATGTGAAATGAGCCACACAAC-3'; for mouse TNFa: forward, 5'-ACTCCAGGCGGTGCCTATGT-3', and reverse, 5'-GTGAGGGTCTGGGCCATAGAA-3'; for mouse GAPDH: forward, 5'-TGTGTCCGTCGTGGATCTGA-3', and reverse, 5'-TTGCTGTTGAAGTCGCAGGAG-3'

\section{Statistical analysis}

Data are expressed by a dot plot with median. Comparison between groups was performed using the Mann-Whitney $U$ test. The Steel-Dwass test was used for nonparametric multiple comparisons among groups. To analysis the relationship between variables, Spearman's rank correlation coefficient was calculated. All statistical analyses were conducted using GraphPad Prism version 7 (GraphPad Software Inc, Sac Diego, California, USA) or JMP Pro version 16 (SAS Institute Inc, Tokyo, Japan). $P<0.05$ was considered significant.

\section{Results}

\section{LILRB4 expression on interstitial macrophages was elevated in COPD patients.}


Because which types of leukocytes expressed LILRB4 in human lung were not clarified, we first examined the expression of LILRB4 on each type of leukocyte in single cell suspensions of normal lung tissue from the patients who received pneumonectomy for lung cancer. Among leukocytes, LILRB4 was clearly expressed on dendritic cells, monocytes, alveolar macrophages (AMs) and interstitial macrophages (IMs) (Fig. 1a-c). We then tried to examine whether the expression of LILRB4 was changed according to the smoking status and prevalence of COPD. We focused on monocytes and macrophages because it has been reported that these cells, especially lung macrophages, are involved in the pathogenesis of COPD [1]. We also had to exclude dendritic cells from further analyses because they were a relatively rare cell population and we could not harvest enough cells from every lung tissue sample for analyses. We compared LILRB4 expression on monocytes, AMs and IMs among non-smokers, non-COPD smokers, and COPD patients. The clinical characteristics of the human studies are shown in Table.

Table. Patients' characteristics for analysis of LILRB4 expression on human lung macrophages

\begin{tabular}{|lllll|}
\hline Characteristics & $\begin{array}{l}\text { never-smokers } \\
(\mathrm{n}=21)\end{array}$ & $\begin{array}{l}\text { non-COPD smokers } \\
(\mathrm{n}=16)\end{array}$ & $\begin{array}{l}\text { COPD } \\
(\mathrm{n}=14)\end{array}$ & $P$ Value \\
\hline Age (years) & $68.5 \pm 8.7$ & $67.6 \pm 5.5$ & $75.5 \pm 3.7$ & $<0.001$ \\
\hline Male / Female & $3 / 18$ & $13 / 3$ & $13 / 1$ & $<.0001$ \\
\hline Smoking (pack-years) & 0 & $39.6 \pm 29.2$ & $48.4 \pm 32.0$ & $<.0001$ \\
\hline FVC (L) & $2.8 \pm 0.7$ & $3.2 \pm 0.9$ & $3.2 \pm 0.5$ & 0.017 \\
\hline FEV1 (L) & $2.2 \pm 0.6$ & $2.6 \pm 0.4$ & $2.1 \pm 0.3$ & 0.004 \\
\hline FEV1 / FVC (\%) & $83.9 \pm 6.2$ & $95.9 \pm 11.0$ & $63.5 \pm 5.7$ & $<.0001$ \\
\hline FEV1 (\% of predicted value) & $108.5 \pm 19.3$ & $91.5 \pm 8.6$ & $82.6 \pm 9.4$ & $<.0001$ \\
\hline \% DLCO & $97.1 \pm 17.2$ & $86.4 \pm 19.5$ & $93.1 \pm 33.6$ & N.S. \\
\hline \% DLCO / VA (\% predicted value) & $103.7 \pm 16.3$ & $93.5 \pm 28.9$ & $79.7 \pm 23.4$ & N.S. \\
\hline GOLD stage (I / II) & - & - & $11 / 3$ & \\
\hline
\end{tabular}

Data are presented as mean \pm standard deviation or number. FVC: forced vital capacity; FEV $\mathrm{F}_{1}$ forced expiratory volume in 1 second; DLCO: diffusing capacity of the lung for carbon monoxide; GOLD: Global Initiative for Chronic Obstructive Lung Disease; N.S.: not significant.

The percentage of LILRB4-positive cells in IMs of the COPD patients was significantly higher than in those of non-smokers and non-COPD smokers (Fig. 1d and 2a). On the other hand, there were no significant differences in the percentages of LILRB4-positive cells in lung AMs and monocytes between the patient groups (Fig. 2a). 
We next analyzed whether the percentage of LILRB4-positive cells in IMs was correlated with the patients' characteristics including lung function and severity of emphysematous lesions. The percentage of LILRB4-positive cells in IMs was significantly associated with the $\mathrm{FEV}_{1} / \mathrm{FVC}$ ratio and percent predicted $\mathrm{FEV}_{1}\left(\% \mathrm{FEV}_{1}\right)$ (Fig. 2b). The percent predicted DLCO/VA (\%DLCO/VA) had a significant negative correlation with the percentage of LILRB4-positive cells in IMs (Fig. 2b). We then used the Goddard score to examine the severity of emphysematous lesions by analyzing low attenuation areas on CT images and their correlation with the existence of LILRB4-positive IMs. The severity of emphysematous lesions was well correlated with the percentage of LILRB4-positive cells in IMs (Fig. 2c). The percentage of LILRB4positive cells in IMs did not significantly correlate with the smoking amount or age (Fig. 2c). These results suggested that the severity of emphysematous lesions was correlated with the accumulation of LILRB4positive IMs.

\section{LILRB4-deficient mice show exacerbation of emphysema formation induced by elastase administration.}

The correlation between the severity of emphysematous lesions and the accumulation of LILRB4-positive IMs in human lungs suggested that LILRB4 could have a role in the pathogenesis of emphysema. We then decided to elucidate whether LILRB4 was involved in the pathogenesis of emphysematous lesions. To answer this question, we utilized LILRB4-deficient (LILRB4 ${ }^{--}$) mice and analyzed an elastase-induced emphysema mouse model. We first examined the LILRB4 expression on leukocytes in a mouse lung single cell suspension prepared by enzymatic digestion. In the mouse lungs, LILRB4 was also expressed on neutrophils, natural killer cells, and eosinophils, in addition to macrophages, monocytes and dendritic cells (Fig. 3a-b). We distinguished IMs from AMs by cell surface markers as previously reported [31] and examined the expression of LILRB4 on mouse IMs, finding that IMs expressing LILRB4 also existed in mouse lungs (Fig. 3a and 3c). We further examined the change of expression of LILRB4 on IMs in an elastase-induced emphysema mouse model. As in the lungs of human COPD patients, the percentage of LILRB4-positive cells in IMs significantly increased after the administration of elastase (Fig. 3c).

We then examined the emphysema formation and the accumulation of inflammatory cells in the airway of the elastase-induced emphysema model. We measured both the mean linear intercept (MLI) by histopathological analysis and the percentage of the low attenuation area (LAA) in the lung field by CT at 21 days after the elastase administration. We found that both indicators, MLI and LAA, were significantly higher in LILRB4 ${ }^{-/-}$mice than to those in wild-type mice, indicating that the emphysematous lesion was exacerbated by the deficiency of LILRB4 (Fig. 4a-d). These data suggested that LILRB4 may have a protective function against emphysema formation in the elastase-induced mouse model.

We also examined inflammatory cell accumulation in the airway because it was possible that the exacerbated emphysema in LILRB4 $\%$ mice might have been due to the exacerbated inflammation induced by elastase. We performed BAL on day 7 and examined the number of the cells in BAL fluids. The numbers of total cells, as well as macrophages and neutrophils, were significantly elevated in the BAL fluid by elastase administration in both the wild-type and LILRB $4^{--}$mice. However, there were no significant differences in the cell counts between the wild-type and LILRB4 ${ }^{-/-}$mice (Fig. 5a-c). We further 
examined the levels of mRNA expression from pro-inflammatory cytokines (IL-1 $\beta$ and TNF- $\alpha$ ) and an antiinflammatory cytokine (IL-10) in the whole lungs of an emphysema model. The levels of IL-1 $\beta$ and TNF- $\alpha$, but not those of IL-10, were significantly increased by the administration of elastase (Fig. 6a). In an elastase-induced emphysema model, the level of IL-10, but not those of inflammatory cytokines, was higher in LILRB4 ${ }^{-/-}$mice compared with wild-type mice (Fig. 6b). We also examined isolated lung IMs to determine the levels of cytokine mRNA because it has been reported that lung IM is a major producer of IL-10 [35]. Isolated IMs from elastase administered LILRB4 ${ }^{-/-}$mice showed similar levels of IL-10 and TNF$a$, although they showed a higher level of IL-1 $\beta$ (Fig. $6 \mathrm{c}$ ). These data suggested that the exacerbation of emphysema in LILRB4 ${ }^{-/}$mice was not due to the aggravation of inflammatory cell accumulation and inflammatory cytokine production.

\section{The deficiency of LILRB4 enhanced MMP-12 production in a mouse emphysema model.}

To explore the cause of the exacerbated emphysematous lesions in LILRB4 ${ }^{-/}$mice, we focused on matrix metalloprotease 12 (MMP-12). MMP-12 is a protease associated with emphysema that is elevated in the sputum and BAL of COPD patients [36-39]. In animal models, emphysema is not induced by smoking stimulation in MMP-12 knockout mice [40].A recent investigation has revealed that IM rather than AM is the major producer of MMP-12 in lungs [41]. We examined the expression level of MMP-12 mRNA in whole lungs. The expression level of MMP-12 mRNA in the whole lung of LILRB4 ${ }^{-/}$mice in the emphysema model was significantly higher than that in wild-type mice (Fig. 7a). We then isolated IMs from digested lungs of the emphysema model and examined the levels of MMP-12 mRNA. LILRB4 $4^{-/-}$IMs had significantly higher levels of MMP-12 mRNA than wild-type IMs (Fig. 7b). These results suggested that the deficiency of LILRB4 enhanced the upregulation of MMP-12 by IMs in the lungs of the emphysema model, which may have caused the exacerbation of emphysematous lesions.

\section{Discussion}

In this study, we focused on LILRB4, one of the inhibitory immune-receptors, and tried to determine the changes in expression of LILRB4 and its role in the pathogenesis of COPD. We found that monocyte linage cells including macrophages expressed LILRB4 in the human lungs. Among monocyte-lineage cells, the percentage of LILRB4-positive cells in total lung IMs was significantly higher than that of nonsmokers or non-COPD smokers. The severity of emphysematous lesions was significantly correlated with the percentage of LILRB4-positive cells in total lung IMs, suggesting that the severity of emphysematous lesions was correlated with the lung accumulation of LILRB4-positive IMs in COPD patients. For further investigation to determine the role of LILRB4 in the pathogenesis of COPD and its emphysematous lesions, we analyzed the elastase-induced emphysema mouse model using LILRB4 ${ }^{-/-}$mice. The levels of LILRB4 were also elevated on the IMs of the mouse model. Interestingly, the deficiency of LILRB4 significantly exacerbated the emphysematous lesions, although the deficiency of LILRB4 did not affect the accumulation of inflammatory cells in the airways. We found that the level of the expression of MMP12 mRNA in the whole lung of LILRB4 ${ }^{-/-}$mice as well as lung IMs in the emphysema model was 
significantly higher than the wild-type, suggesting that the deficiency of LILRB4 enhanced the production of MMP-12 by lung IMs and contributed to the exacerbation of emphysematous lesions. The results of our study suggests that LILRB4, which is upregulated on lung IMs in COPD patients, may have a protective effect against emphysema formation through decreasing MMP-12 expression.

It has been well reported that lung macrophages are involved in the pathogenesis of emphysematous lesions in both human and animal models [42]. Recent studies have revealed that there are IMs in addition to AMs, the classical lung macrophages, in the lungs of mouse and human, and IMs have distinctively different functions than AMs $[43,44]$. It has been recently reported that IM is a major producer of MMP-12 in the lungs in a mouse emphysema model [41]. Our results suggest that LILRB4, which is upregulated on lung IMs in both human COPD patients and a mouse elastase-induced emphysema model, has a protective effect against the formation of emphysematous lesions through the attenuation of MMP-12 production, mainly by IMs.

We have not elucidated how the intracellular signaling via LILRB4 attenuates the expression of MMP-12 in lung IMs. IL-4 produced by basophils induces the differentiation of accumulated monocytes into MMP12 producing IMs in a mouse model of emphysema induced by elastase [41]. STAT6-deficient mice did not show the upregulation of MMP12 mRNA induced by IL-4 in bone marrow-derived macrophages, and chromatin immunoprecipitation-qPCR analyses revealed that IL-4 induced STAT6 binding to the promoter region of MMP12, suggesting that IL-4 mediates MMP-12 expression through STAT6 activation [45]. A protein-tyrosine phosphatase SHP-1 is recruited to LILRB4 through its ITIMs upon crosslinking [5]. A previous study reported that overexpression of SHP-1 reduced both the IL-4-dependent Stat6 activation and Stat6-mediated upregulation of IL-4 responsive genes [46]. Therefore, it is possible that LILRB4 attenuates the expression of MMP-12 in lung IMs through SHP-1 activation recruited to its ITIMs by the inhibition of IL-4-induced STAT6 activation.

Our studies found that the percentage of LILRB4-positive cells in total lung IMs was significantly increased in both COPD patients and a mouse model of emphysema. We have not yet obtained clear evidence to explain how LILRB4 is upregulated on lung IMs during COPD. However, both previous reports $[11,19,21]$ and an analysis of the promoter and enhancer region of LILRB4 provided in the public database likely suggests that LILRB4 may be upregulated by inflammatory stimuli including cytokines. A previous report showed that LILRB4 is upregulated on hepatocytes in nonalcoholic fatty liver disease (NAFLD), a chronic inflammatory disease of the liver [19]. In a high-fat diet induced NAFLD model in mice, the hepatocytes on which LILRB4 is upregulated by inflammatory stimuli showed an improvement from insulin resistance, glucose metabolic disorder, hepatic lipid accumulation, as well as inflammatory responses [19]. This negative feedback-loop is operated by SHP-1 recruitment to LILRB4 to inhibit TRAF6 ubiquitination and subsequent inactivation of NF-KB and mitogen-activated protein kinase cascades, which results in the attenuation of inflammatory responses [19]. The fact that there are binding sites for both AP-1 and NF-KB, which are the transcription factors activated by inflammatory cytokines (https://www.genecards.org/), also supports the idea that LILRB4 is upregulated by inflammatory stimuli and operates the negative feedback through SHP-1. 
This study has several limitations. First, for a human study, the sample size is relatively small and the COPD group had only GOLD stage I and II patients. However, analyses of single lung cells harvested from human lung samples including the lungs of COPD patients are valuable for exploring the pathogenesis of actual human COPD and emphysematous lesions, even if the sample size is small. Second, a mouse model of emphysema induced by elastase, in which both inflammation and the subsequent formation of emphysematous lesions were subacute, is not an optimal model for human COPD as compared to a cigarette smoke-induced model, although this animal model also shows the upregulation of MMP-12, as found in human COPD patients. Third, although fibronectin has been quite recently identified as a physiological ligand on both human monocytic leukemia cell line THP-1 cells and human primary monocytes [47], the existence of a pathophysiological ligand for LILRB4 on lung IMs in COPD and a mouse emphysema model remains unclear. Further examinations are needed to determine the ligand in order to understand the roles of LILRB4 and its ligand in the pathogenesis of emphysema.

In summary, the severity of emphysematous lesions was correlated with the accumulation of LILRB4positive IMs in COPD patients. The deficiency of LILRB4 exacerbated emphysematous lesions in a mouse model of emphysema. The deficiency of LILRB4 enhanced the production of MMP-12 by lung IMs, which may contribute to the aggravation of emphysematous lesions. Therefore, LILRB4 may have a protective effect against emphysema formation by its involvement in a negative-feedback loop. Further investigation for LILRB4 and its ligand on IMs may elucidate the pathophysiology of COPD and its emphysematous lesions and possibly lead to the discovery of therapeutic targets for COPD.

\section{Abbreviations}

AM: Alveolar macrophage; BAL: Bronchoalveolar lavage; BALF: Bronchoalveolar lavage fluid; COPD: chronic obstructive pulmonary disease; CT: Computed tomography; DLCO: Diffusing capacity of the lungs for carbon monoxide; $\mathrm{FEV}_{1}$ : Forced expiratory volume in one second; $\% \mathrm{FEV}_{1}$ : Percent predicted forced expiratory volume in one second; FVC: Forced vital capacity; GOLD: Global Initiative for Chronic Obstructive Lung Disease; IL-1: Interleukin-1ß; IL-10: Interleukin-10; ILT-3: immunoglobulin-like transcripts 3; IM: Interstitial macrophage; LAA: low attenuation area; LILRB4: Leukocyte immunoglobulin-like receptor B4; MLI: mean linear intercept; MMP-12: Matrix metalloprotease 12; NAFLD: Nonalcoholic fatty liver disease; STAT6: Signal transducer and activator of transcription 6; SHP-1: SH2-containing protein tyrosine phosphatase-1; TNF-a: Tumor necrosis factor-a; TRAF6: TNF receptor-associated factor 6; VA: Alveolar volume.

\section{Declarations}

Ethics approval and consent to participate

The study with human subjects was approved by the Ethics Committee at Tohoku University School of Medicine (2017-1-352). Written informed consent was obtained from all patients. All animal protocols for 
the experiments in this study were reviewed and approved by the Animal Studies Committee of Tohoku University.

Consent for publication

Not applicable.

Availability of data and materials

The datasets used and analysed during the current study are available from the corresponding author on reasonable request.

Competing interests

The authors declare that they have no competing interests.

Funding

This work was supported by Grants-in-Aid for Scientific Research (18K08134 to M. Yamada, 18K15914 to Y. Mitsuhashi, $18 \mathrm{~K} 15943$ to T. Makiguchi, $20 \mathrm{H} 03684$ to S. Hisatoshi, A. Mitsune to $21 \mathrm{~K} 16131$ ) from the Japan Society for the Promotion of Science (JSPS).

Authors' contributions

A.M., M.Y., and H.S. designed and directed the experiments. A.M., M.Y., N.F., K.I., Y.M., T.I., T.N., A.K., T.T., Y.O. and S.S. prepared the specimens and clinical data. A.M., M.Y., N.F., A.S., S.M., and K.I performed the experiments in both human and mouse model samples. A.M., M.Y., N.F., H.S., S.E., T.T., and M.I. analyzed and interpreted the data. All authors participated in writing and proofreading the manuscript.

Acknowledgements

We thank Mr. Brent K. Bell for critical reading of the manuscript and for language assistance. We acknowledge the support of the Biomedical Research Unit of Tohoku University Hospital and Biomedical Research Core of Tohoku University Graduate School of Medicine.

\section{References}

1. Barnes PJ. Immunology of asthma and chronic obstructive pulmonary disease. Nat Rev Immunol. 2008;8:183-92.

2. Hogg JC, Timens W. The pathology of chronic obstructive pulmonary disease. Annu Rev Pathol. 2009;4:435-59.

3. Nici L, Mammen MJ, Charbek E, Alexander PE, Au DH, Boyd CM, et al. Pharmacologic Management of Chronic Obstructive Pulmonary Disease. An Official American Thoracic Society Clinical Practice Guideline. Am J Respir Crit Care Med. 2020;201:e56-e69. 
4. Barnes PJ. Corticosteroid resistance in patients with asthma and chronic obstructive pulmonary disease. J Allergy Clin Immunol. 2013;131:636-45.

5. Cella M, Dohring C, Samaridis J, Dessing M, Brockhaus M, Lanzavecchia A, et al. A novel inhibitory receptor (ILT3) expressed on monocytes, macrophages, and dendritic cells involved in antigen processing. J Exp Med. 1997;185:1743-51.

6. Katz HR. Inhibition of pathologic inflammation by leukocyte Ig-like receptor B4 and related inhibitory receptors. Immunol Rev. 2007;217:222-30.

7. van der Touw W, Chen HM, Pan PY, Chen SH. LILRB receptor-mediated regulation of myeloid cell maturation and function. Cancer Immunol Immunother. 2017;66:1079-87.

8. Ravetch JV, Lanier LL. Immune inhibitory receptors. Science. 2000;290:84-9.

9. Breslow RG, Rao JJ, Xing W, Hong DI, Barrett NA, Katz HR. Inhibition of Th2 adaptive immune responses and pulmonary inflammation by leukocyte Ig-like receptor B4 on dendritic cells. $J$ Immunol. 2010;184:1003-13.

10. Norris HH, Peterson ME, Stebbins CC, McConchie BW, Bundoc VG, Trivedi S, et al. Inhibitory receptor gp49B regulates eosinophil infiltration during allergic inflammation. J Leukoc Biol. 2007;82:1531-41.

11. Qiu T, Zhou J, Wang T, Chen Z, Ma X, Zhang L, et al. Leukocyte immunoglobulin-like receptor B4 deficiency exacerbates acute lung injury via NF-kappaB signaling in bone marrow-derived macrophages. Biosci Rep. 2019;39.

12. Singh L, Muise ES, Bhattacharya A, Grein J, Javaid S, Stivers P, et al. ILT3 (LILRB4) Promotes the Immunosuppressive Function of Tumor-Educated Human Monocytic Myeloid-Derived Suppressor Cells. Mol Cancer Res. 2021;19:702-16.

13. Sharma N, Atolagbe OT, Ge Z, Allison JP. LILRB4 suppresses immunity in solid tumors and is a potential target for immunotherapy. J Exp Med. 2021;218:e20201811.

14. Deng M, Gui X, Kim J, Xie L, Chen W, Li Z, et al. LILRB4 signalling in leukaemia cells mediates T cell suppression and tumour infiltration. Nature. 2018;562:605-09.

15. de Goeje PL, Bezemer K, Heuvers ME, Dingemans AC, Groen HJ, Smit EF, et al. Immunoglobulin-like transcript 3 is expressed by myeloid-derived suppressor cells and correlates with survival in patients with non-small cell lung cancer. Oncoimmunology. 2015;4:e1014242.

16. Inui M, Sugahara-Tobinai A, Fujii H, Itoh-Nakadai A, Fukuyama H, Kurosaki T, et al. Tolerogenic immunoreceptor ILT3/LILRB4 paradoxically marks pathogenic auto-antibody-producing plasmablasts and plasma cells in non-treated SLE. Int Immunol. 2016;28:597-604.

17. Tian Y, Meng L, Wang Y, Li B, Yu H, Zhou Y, et al. Graft-versus-host disease depletes plasmacytoid dendritic cell progenitors to impair tolerance induction. J Clin Invest. 2021;131:e136774.

18. Chang CC, Ciubotariu R, Manavalan JS, Yuan J, Colovai Al, Piazza F, et al. Tolerization of dendritic cells by T(S) cells: the crucial role of inhibitory receptors ILT3 and ILT4. Nat Immunol. 2002;3:237-43.

19. Lu Y, Jiang Z, Dai H, Miao R, Shu J, Gu H, et al. Hepatic leukocyte immunoglobulin-like receptor B4 (LILRB4) attenuates nonalcoholic fatty liver disease via SHP1-TRAF6 pathway. Hepatology. 
2018;67:1303-19.

20. Li Z, Zhao M, Li T, Zheng J, Liu X, Jiang Y, et al. Decidual Macrophage Functional Polarization during Abnormal Pregnancy due to Toxoplasma gondii: Role for LILRB4. Front Immunol. 2017;8:1013.

21. Brown DP, Jones DC, Anderson KJ, Lapaque N, Buerki RA, Trowsdale J, et al. The inhibitory receptor LILRB4 (ILT3) modulates antigen presenting cell phenotype and, along with LILRB2 (ILT4), is upregulated in response to Salmonella infection. BMC Immunol. 2009;10:56.

22. Goddard PR, Nicholson EM, Laszlo G, Watt I. Computed tomography in pulmonary emphysema. Clin Radiol. 1982;33:379-87.

23. Suzuki T, Suzuki S, Fujino N, Ota C, Yamada M, Suzuki T, et al. c-Kit immunoexpression delineates a putative endothelial progenitor cell population in developing human lungs. American Journal of Physiology-Lung Cellular and Molecular Physiology. 2014;306:L855-L65.

24. Fujino N, Kubo H, Ota C, Suzuki T, Suzuki S, Yamada M, et al. A Novel Method for Isolating Individual Cellular Components from the Adult Human Distal Lung. American Journal of Respiratory Cell and Molecular Biology. 2012;46:422-30.

25. Numakura T, Sugiura H, Akaike T, Ida T, Fujii S, Koarai A, et al. Production of reactive persulfide species in chronic obstructive pulmonary disease. Thorax. 2017;72:1074-83.

26. Onodera K, Sugiura H, Yamada M, Koarai A, Fujino N, Yanagisawa S, et al. Decrease in an anti-ageing factor, growth differentiation factor 11, in chronic obstructive pulmonary disease. Thorax. 2017;72:893-904.

27. Kasai S, Inui M, Nakamura K, Kakizaki Y, Endo S, Nakamura A, et al. A novel regulatory role of gp49B on dendritic cells in T-cell priming. Eur J Immunol. 2008;38:2426-37.

28. Moro K, Ealey KN, Kabata H, Koyasu S. Isolation and analysis of group 2 innate lymphoid cells in mice. Nat Protoc. 2015;10:792-806.

29. Takei Y, Yamada M, Saito K, Kameyama Y, Sugiura H, Makiguchi T, et al. Increase in circulating ACEpositive endothelial microparticles during acute lung injury. Eur Respir J. 2019;54:1801188.

30. Yu YR, Hotten DF, Malakhau Y, Volker E, Ghio AJ, Noble PW, et al. Flow Cytometric Analysis of Myeloid Cells in Human Blood, Bronchoalveolar Lavage, and Lung Tissues. Am J Respir Cell Mol Biol. 2016;54:13-24.

31. Yu YR, O'Koren EG, Hotten DF, Kan MJ, Kopin D, Nelson ER, et al. A Protocol for the Comprehensive Flow Cytometric Analysis of Immune Cells in Normal and Inflamed Murine Non-Lymphoid Tissues. PLoS One. 2016;11:e0150606.

32. Dewhurst JA, Lea S, Hardaker E, Dungwa JV, Ravi AK, Singh D. Characterisation of lung macrophage subpopulations in COPD patients and controls. Sci Rep. 2017;7:7143.

33. Thurlbeck WM. Internal surface area and other measurements in emphysema. Thorax. 1967;22:48396.

34. Kobayashi S, Fujinawa R, Ota F, Kobayashi S, Angata T, Ueno M, et al. A single dose of lipopolysaccharide into mice with emphysema mimics human chronic obstructive pulmonary 
disease exacerbation as assessed by micro-computed tomography. Am J Respir Cell Mol Biol. 2013;49:971-7.

35. Sabatel C, Radermecker C, Fievez L, Paulissen G, Chakarov S, Fernandes C, et al. Exposure to Bacterial CpG DNA Protects from Airway Allergic Inflammation by Expanding Regulatory Lung Interstitial Macrophages. Immunity. 2017;46:457-73.

36. Chaudhuri R, McSharry C, Brady J, Donnelly I, Grierson C, McGuinness S, et al. Sputum matrix metalloproteinase-12 in patients with chronic obstructive pulmonary disease and asthma: relationship to disease severity. J Allergy Clin Immunol. 2012;129:655-63 e8.

37. Molet S, Belleguic C, Lena H, Germain N, Bertrand CP, Shapiro SD, et al. Increase in macrophage elastase (MMP-12) in lungs from patients with chronic obstructive pulmonary disease. Inflamm Res. 2005;54:31-6.

38. Babusyte A, Stravinskaite K, Jeroch J, Lotvall J, Sakalauskas R, Sitkauskiene B. Patterns of airway inflammation and MMP-12 expression in smokers and ex-smokers with COPD. Respir Res. 2007;8:81.

39. Finlay GA, O'Driscoll LR, Russell KJ, D'Arcy EM, Masterson JB, FitzGerald MX, et al. Matrix metalloproteinase expression and production by alveolar macrophages in emphysema. Am J Respir Crit Care Med. 1997;156:240-7.

40. Hautamaki RD, Kobayashi DK, Senior RM, Shapiro SD. Requirement for macrophage elastase for cigarette smoke-induced emphysema in mice. Science. 1997;277:2002-4.

41. Shibata S, Miyake K, Tateishi T, Yoshikawa S, Yamanishi Y, Miyazaki Y, et al. Basophils trigger emphysema development in a murine model of COPD through IL-4-mediated generation of MMP-12producing macrophages. Proc Natl Acad Sci U S A. 2018;115:13057-62.

42. Ni L, Dong C. Roles of Myeloid and Lymphoid Cells in the Pathogenesis of Chronic Obstructive Pulmonary Disease. Front Immunol. 2018;9:1431.

43. Liegeois M, Legrand C, Desmet CJ, Marichal T, Bureau F. The interstitial macrophage: A longneglected piece in the puzzle of lung immunity. Cell Immunol. 2018;330:91-96.

44. Schyns J, Bureau F, Marichal T. Lung Interstitial Macrophages: Past, Present, and Future. J Immunol Res. 2018;2018:5160794.

45. Nakagomi D, Suzuki K, Meguro K, Hosokawa J, Tamachi T, Takatori H, et al. Matrix metalloproteinase 12 is produced by M2 macrophages and plays important roles in the development of contact hypersensitivity. J Allergy Clin Immunol. 2015;135:1397-400.

46. Haque SJ, Harbor P, Tabrizi M, Yi T, Williams BR. Protein-tyrosine phosphatase Shp-1 is a negative regulator of IL-4- and IL-13-dependent signal transduction. J Biol Chem. 1998;273:33893-6.

47. Su MT, Inui M, Wong YL, Takahashi M, Sugahara-Tobinai A, Ono K, et al. Blockade of checkpoint ILT3/LILRB4/gp49B binding to fibronectin ameliorates autoimmune disease in BXSB/Yaa mice. Int Immunol. 2021:10.1093/intimm/dxab028.

\section{Figures}


a

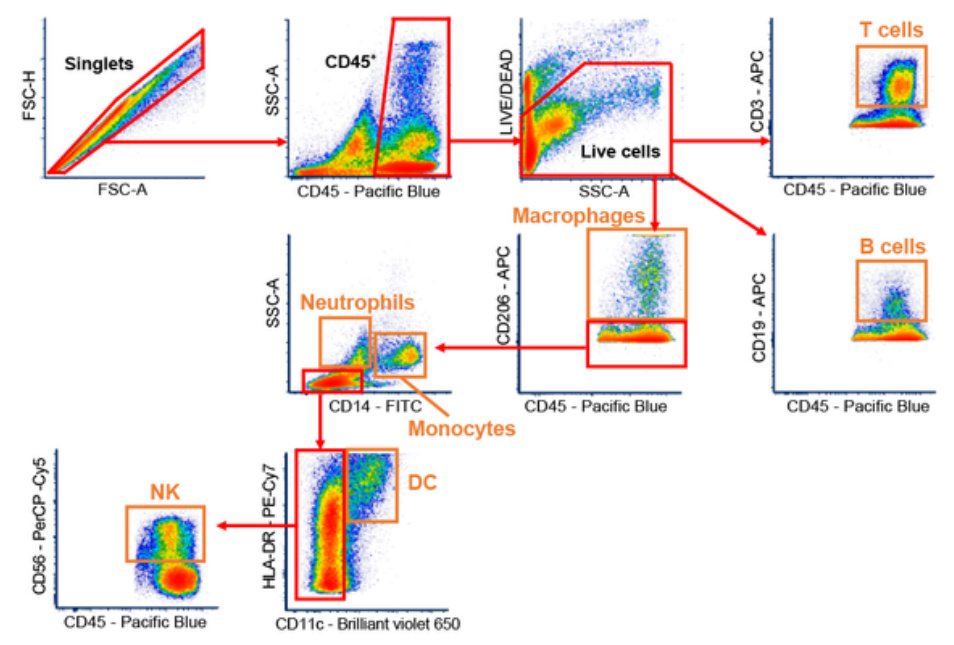

C

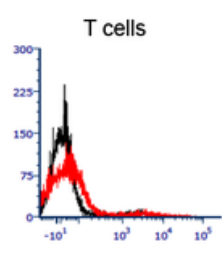

NK

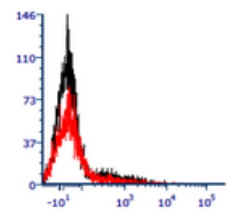

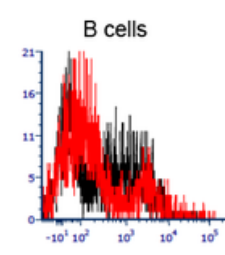

$\mathrm{DC}$

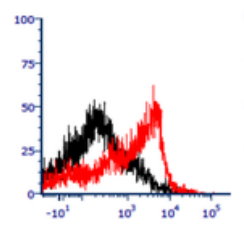

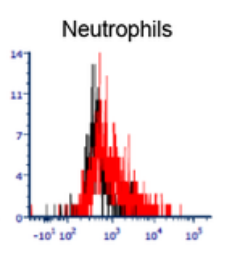

Monocytes

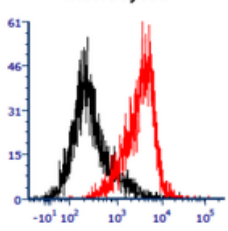

b

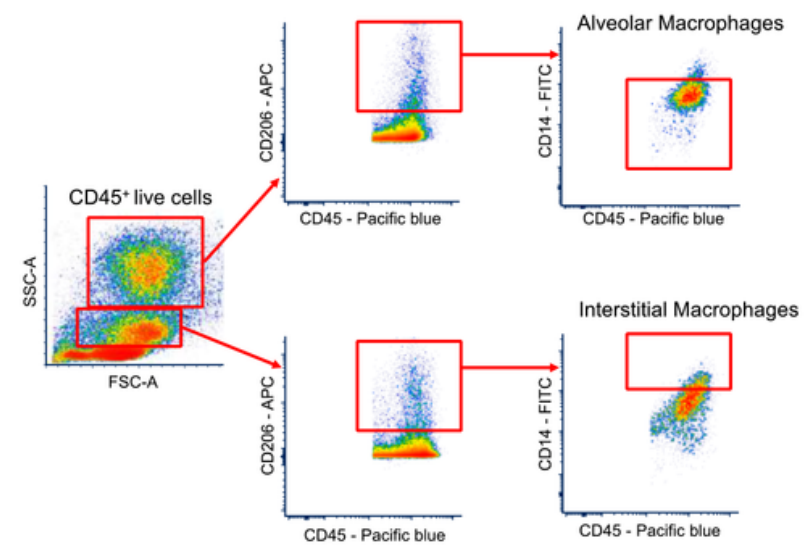

d

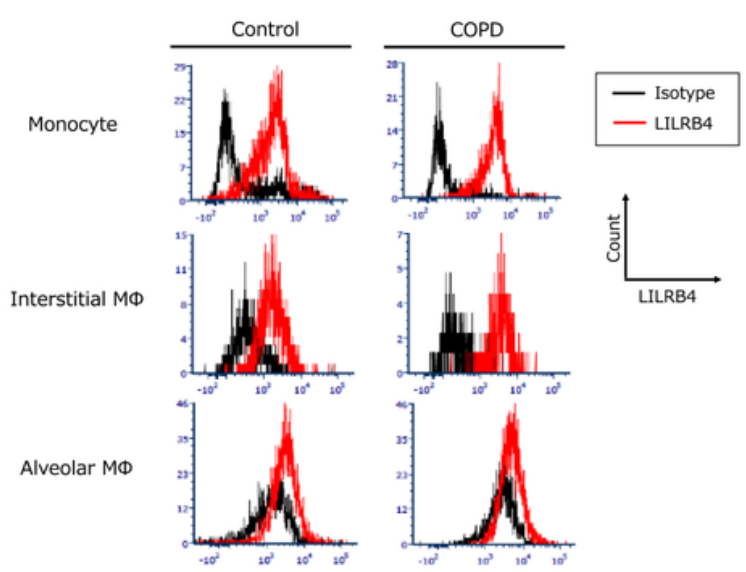

Figure 1

The expression of LILRB4 on lung interstitial macrophages was upregulated in COPD patients. (a) The flow cytometric gating strategy for detecting leukocyte lineages in human lung tissue. (b) The gating strategy of the flow cytometry for detecting human lung macrophages. We defined FSChighCD45+CD206+CD14- cells as alveolar macrophages, and FSCmidCD45+CD206+CD14+ cells as interstitial macrophages. We utilized fluorescence minus one controls to distinguish the positive population from the negative one. (c) Representative histograms of LILRB4 expression on lung T cells, B cells, neutrophils, natural killer cells, dendritic cells, monocytes, and macrophages. Black line indicates staining with an isotype control antibody for anti-LILRB4. (d) Representative histograms of LILRB4 expression on monocyte, alveolar macrophages, and interstitial macrophages in the single cell suspension prepared from the lungs of never-smoker control or COPD patients. NK: natural killer cells; DC: dendritic cells; COPD: chronic obstructive pulmonary disease. 
a

Interstitial Macrophages

Alveolar Macrophages

Monocytes
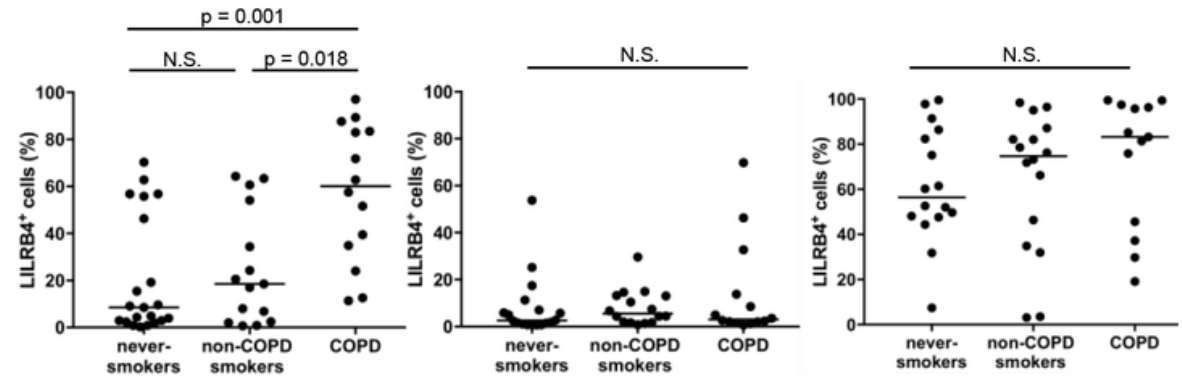

b

$\mathrm{FEV}_{1} / \mathrm{FVC}$

$\% \mathrm{FEV}_{1}$

$\%$ DLCO/VA
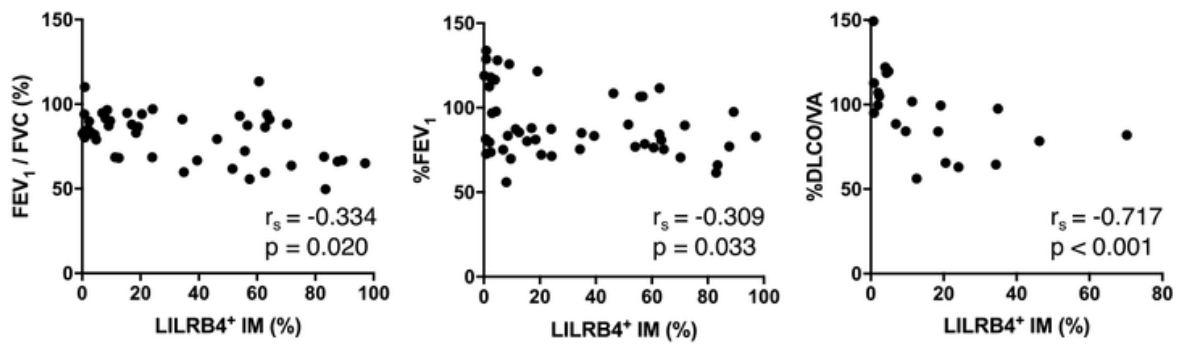

C

LAA

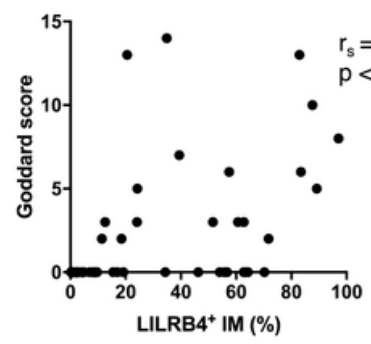

Smoking

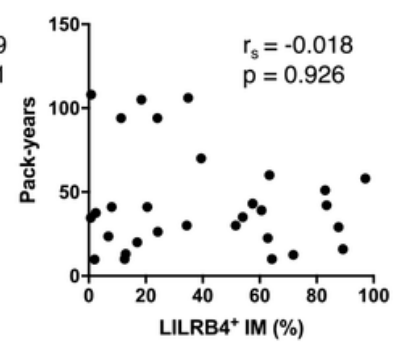

Age

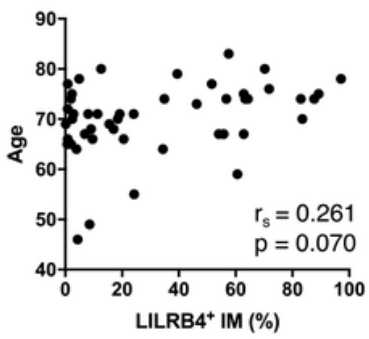

Figure 2

The correlation of the upregulation of LILRB4 expression on interstitial macrophages with the severity of emphysematous lesions. (a) Percentages of LILRB4 expression on interstitial macrophages (IMs, left), alveolar macrophages (AMs, middle), and monocytes (right) in the lungs from never-smokers, non-COPD smokers, and COPD patients. $n=21$ for never-smokers, $n=16$ for non-COPD smokers, $n=14$ for COPD patients. Data are presented as median with a dot for each sample. The Steel-Dwass test was used for nonparametric multiple comparisons among the groups. N.S.: not significant. (b) Correlation analysis of the percentage of LILRB4 positive cells in lung IMs with FEV1/FVC (left), \%FEV1 (middle), or \%DLCO/VA (right). $n=51$ for FEV1/FVC and \%FEV1, $n=21$ for \%DLCO/VA. (c) Correlation analysis between the percentage of LILRB4 positive cells in lung IMs and Goddard score (left), smoking amount (middle), and 
age (right). $\mathrm{N}=51$ for each analysis. To analyze the relationship between variables, the spearman correlation coefficient was used. FEV1: forced expiratory volume in 1 second; FVC: forced vital capacity; DLCO: diffusing capacity of the lung for carbon monoxide; VA: alveolar volume; LAA: low attenuation area.

a
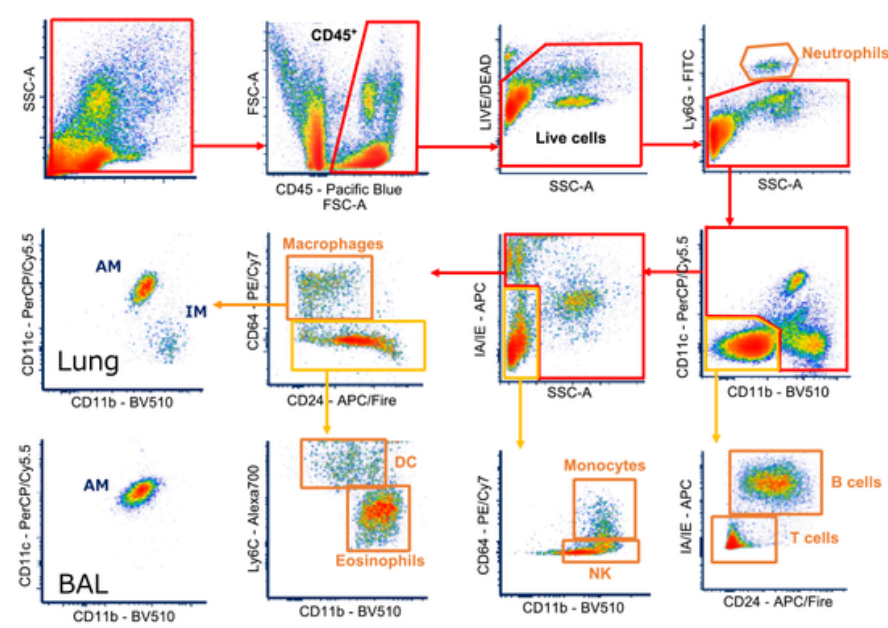

C

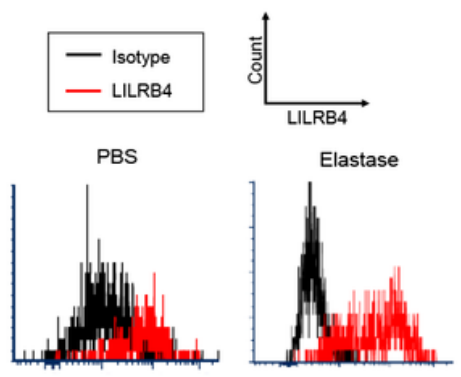

b

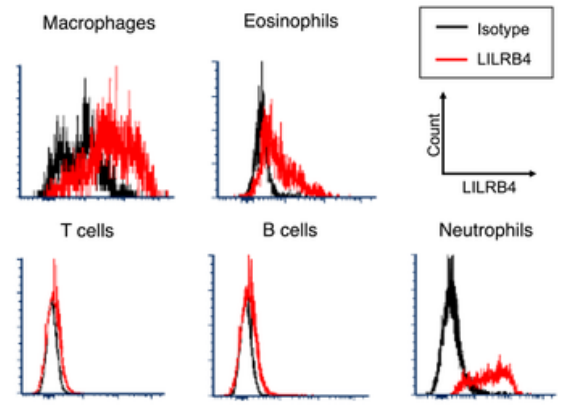

NK
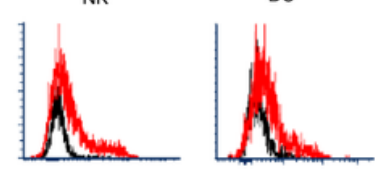

Monocytes

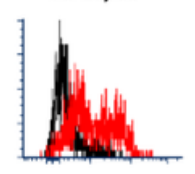

\section{Figure 3}

LILRB4 expression on interstitial macrophages in mouse lungs. (A) Flow cytometric gating strategy for detecting mouse lung hematopoietic cells. We defined CD45+Ly6G-CD64+CD24-CD11b+CD11c- cells as IMs, and CD45+Ly6G-CD64+CD24-CD11bintCD11 c+ cells as AMs. (B) Representative histograms of LILRB4 expression on macrophages, eosinophils, T cells, B cells, neutrophils, natural killer cells, dendritic cells, and monocytes. (C) Representative histograms of LILRB4 expression on IM (left) and the percentage of LILRB4 positive cells on IMs (right) from PBS-treated mice $(n=6)$ and elastase-treated wild-type mice $(n=6)$ seven days after the administration. Data are presented as median with a dot for each sample. Mann-Whitney U test was used for comparison between two groups. AM: alveolar macrophages; IM: interstitial macrophages; NK: natural killer cells; DC: dendritic cells. 
a
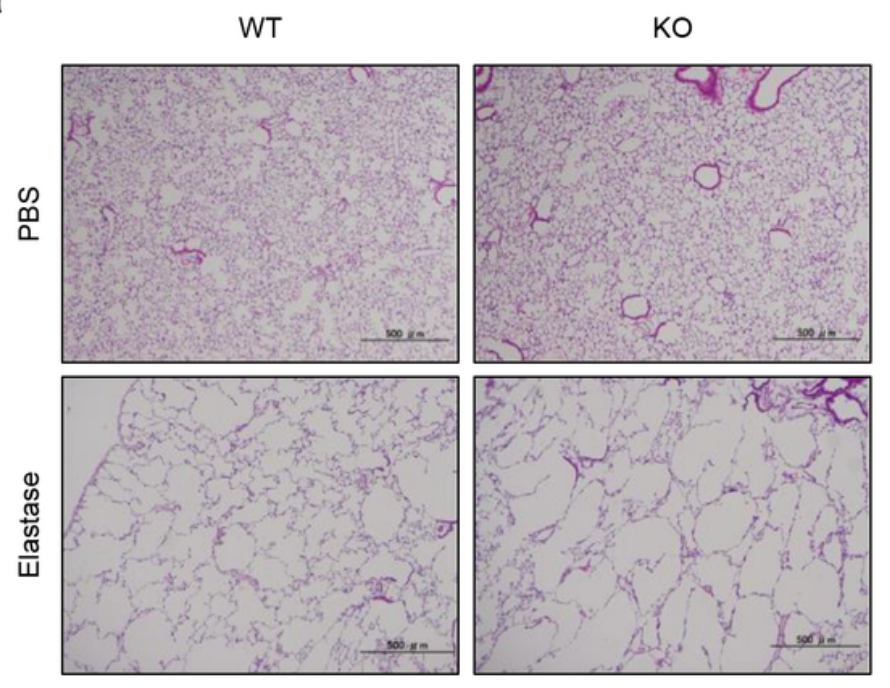

C

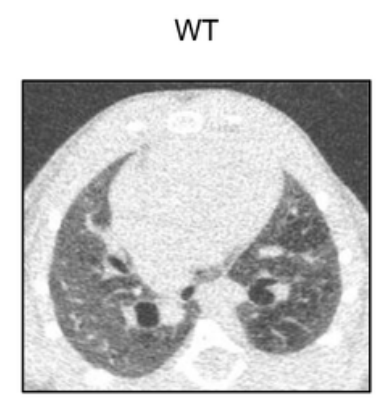

b
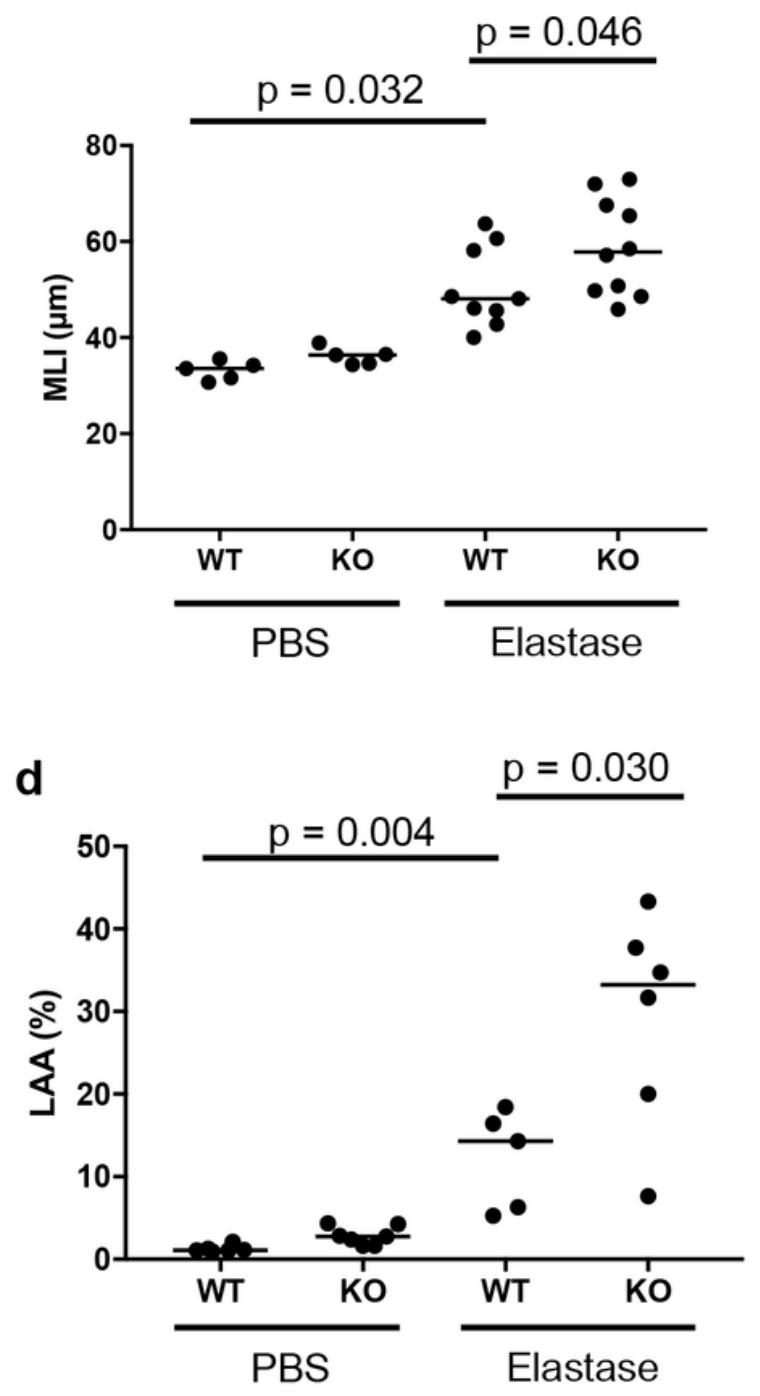

\section{Figure 4}

The deficiency of LILRB4 aggravated emphysematous lesions in the mouse elastase-induced emphysema model. (a) Representative hematoxylin/eosin-stained histological images of the lungs from wild-type or LILRB4-/- mice on day 21 after PBS or elastase intranasal administration. Scale bar: $500 \mu \mathrm{m}$. (b) Mean liner intercepts calculated by analyzing histological images on day 21 after administration. (c) Representative chest CT images of wild-type mice (left) and LILRB4-/- mice (right) on day 21 after intranasal administration of elastase. (d) Low attenuation area (LAA) of CT images on day 21 after administration. Data are presented as median with a dot for each sample. The Steel-Dwass test was used for nonparametric multiple comparisons among the groups. $\mathrm{N}=5$ to 10 per groups. WT: wild-type mice; KO: LILRB4-deficient mice; MLI: mean liner intercept; LAA: low attenuation area. 

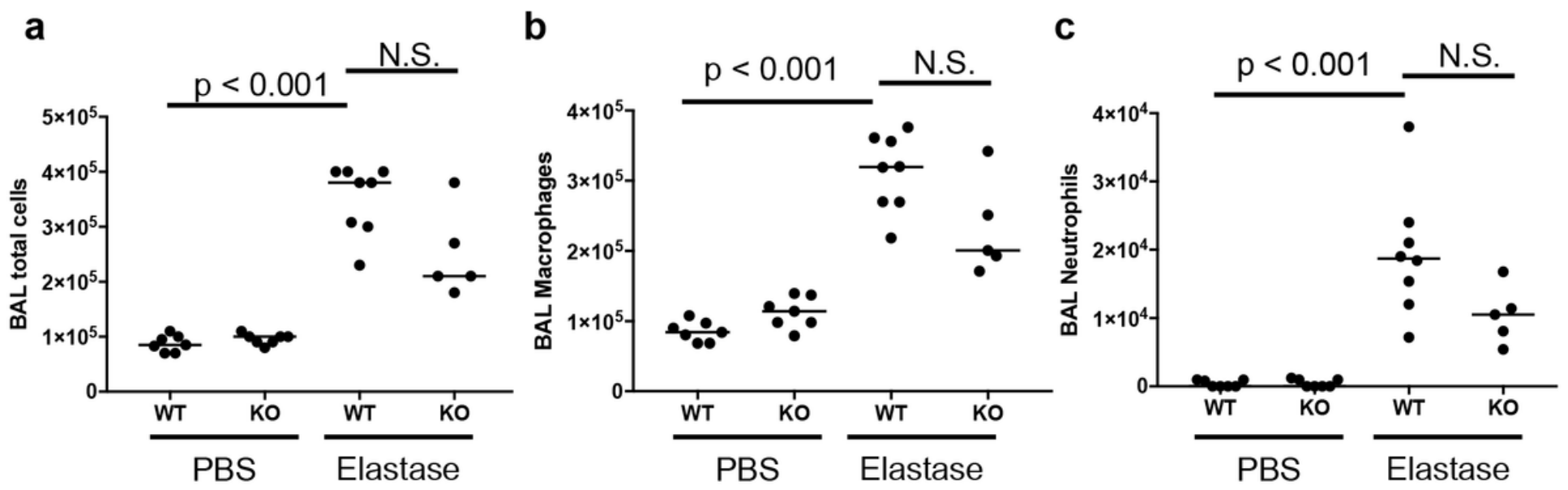

Figure 5

The deficiency of LILRB4 did not affect the accumulation induced by intranasal administration of elastase. BAL was performed on day 7 after the administration of PBS or elastase. The number of total cells (a), macrophages (b), neutrophils (c) in BAL fluids were examined. Data are presented as median with a dot for each sample. The Steel-Dwass test was used for nonparametric multiple comparisons among the groups. $\mathrm{N}=5$ to 8 per groups. WT: wild-type mice; KO: LILRB4-deficient mice. 
a

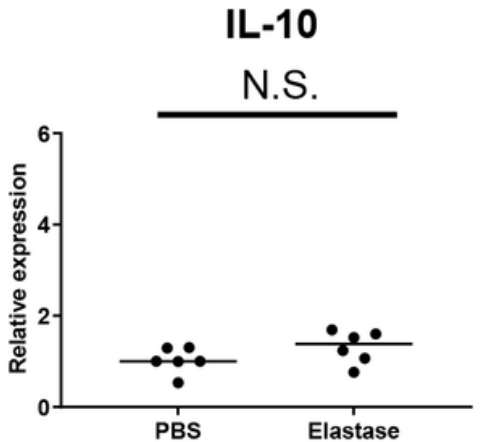

b

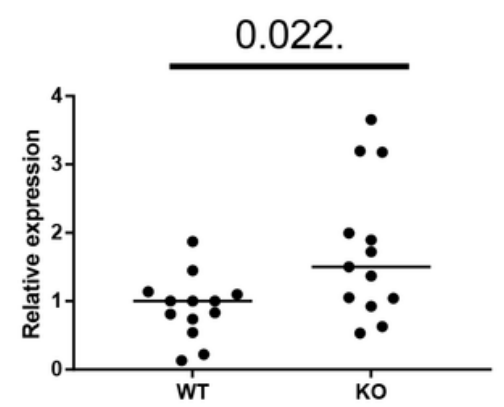

C

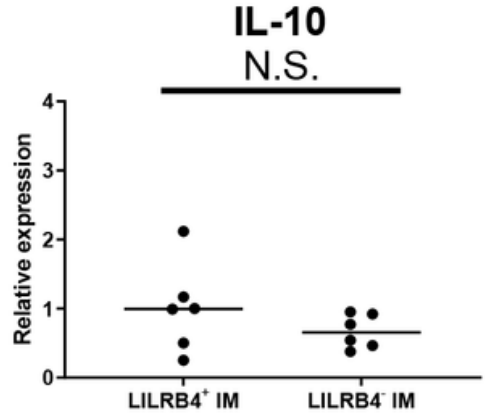

IL-1 $\beta$

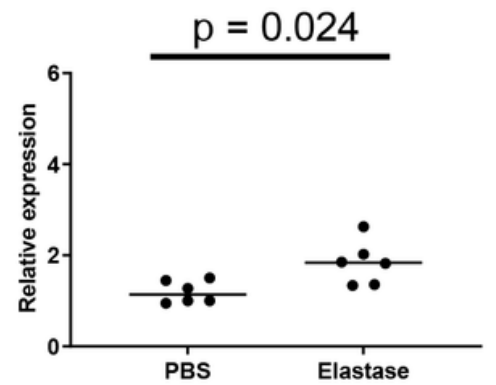

IL-1 $\beta$

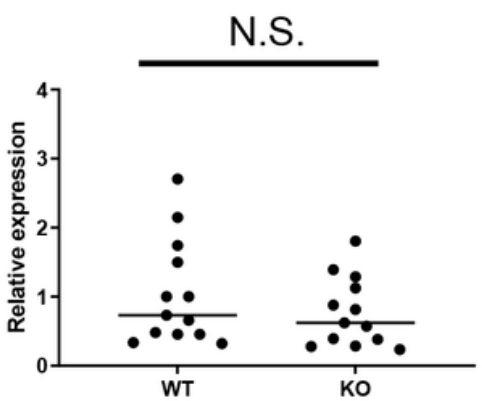

IL-1 $\beta$

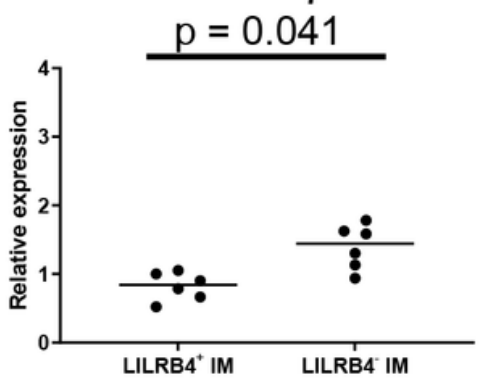

TNF- $\alpha$

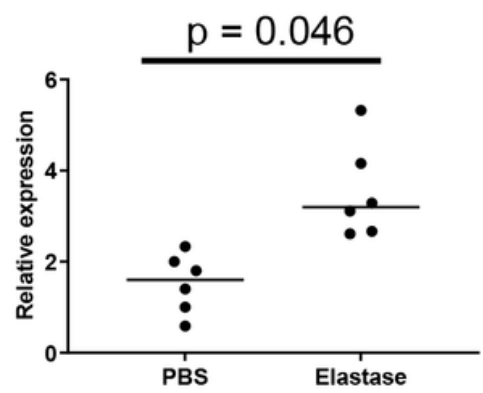

TNF- $\alpha$

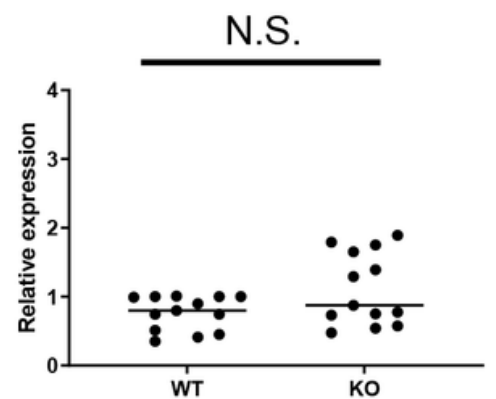

TNF-a

N.S.

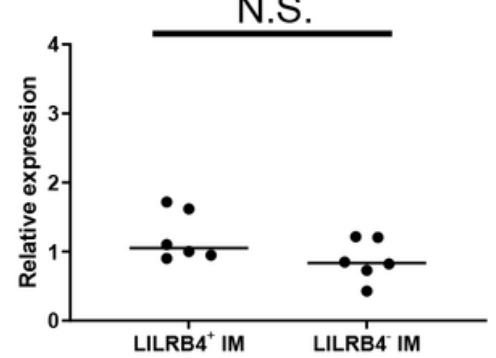

Figure 6

LILRB4-deficient mice enhanced IL-10 mRNA expression. (A) We administered PBS or elastase to wildtype mice and compared IL-10 (left), IL-1 $\beta$ (middle) and TNF-a (right) mRNA expressions. $N=6$ per groups. The reference sample was one of the PBS-treated control samples. (B) Comparison of IL-10 (left), IL-1 $\beta$ (middle) and TNF- $a$ (right) mRNA expressions between wild-type and LILRB4-/- mice on day 7 after elastase administration. $N=13$ per groups. The reference sample was one of the wild-type samples. (C) Comparison of IL-10 (left), IL-1 $\beta$ (middle) and TNF-a (right) mRNA expressions between LILRB4-positive IMs and LILRB4-negative IMs on day 7 after elastase administration. $N=6$ per groups. The reference sample was one of the wild-type samples. Data are presented as median with a dot for each sample and analyzed by Mann-Whitney U test. WT: wild-type mice; KO: LILRB4-deficient mice; IM: interstitial macrophages. 
a

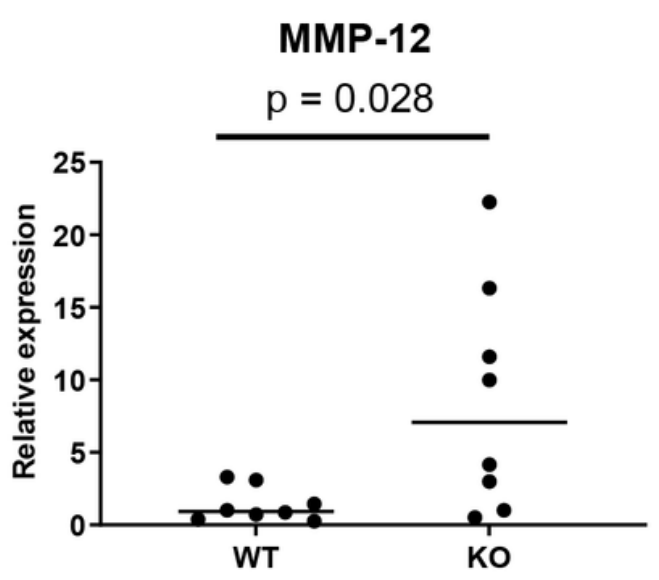

b

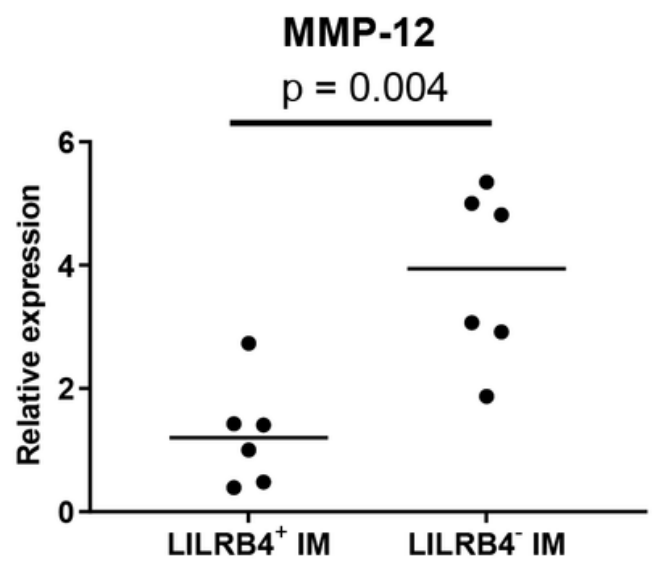

\section{Figure 7}

LILRB4-decifient mice enhanced MMP-12 mRNA expression. (a) MMP-12 mRNA expression between wildtype mice and LILRB4-/- mice on day 7 after elastase administration. The mean value of WT was set to 1 . $\mathrm{N}=8$ per groups. (b) MMP-12 mRNA expression between LILRB4-positive IMs and LILRB4-negative IMs. $\mathrm{N}=6$ per group. Data are presented as median with a dot for each sample. Statistical comparisons were analyzed by Mann-Whitney U test. WT: wild-type mice; KO: LILRB4-deficient mice. 